\title{
Enhanced Stability of MAPbI 3 Perovskite Films with Zirconium Phosphate-Phosphonomethylglycine Nanosheets as Additive
}

Nadir Vanni, Diletta Morelli Venturi, Eros Radicchi, Giulia Quaglia, Elena Cambiotti, Loredana Latterini, Filippo De Angelis* and Ferdinando Costantino*

Nadir Vanni, Diletta Morelli Venturi, Eros Radicchi, Giulia Quaglia, Elena Cambiotti, Dr. Loredana Latterini, Dr. Filippo De Angelis and Dr. Ferdinando Costantino

Department of Chemistry, Biology and Biotechnologies, Università degli Studi di Perugia, via Elce di Sotto, 8 - 06123 Perugia (PG) - Italy

Giulia Quaglia, Elena Cambiotti, Prof. Dr. Loredana Latterini

Nano4Light-Lab - via Elce di Sotto, 8 - 06123 Perugia (PG) - Italy

Dr. Eros Radicchi

Computational Laboratory for Hybrid/Organic Photovoltaics (CLHYO), Istituto CNR di Scienze e Tecnologie Chimiche "Giulio Natta" (CNR-SCITEC), via Elce di Sotto, 8 - 06123 Perugia (PG) - Italy.

Prof. Dr. Filippo De Angelis

CompuNet, Istituto Italiano di Tecnologia, Genova, Italy

E-mail: filippo.deangelis@unipg.it, ferdinando.costantino@unipg.it

Keywords: Perovskite, Solar Energy, Zirconium Phosphonates, Composites.

\section{ABSTRACT}

Methylammonium Lead Iodide perovskite $\left(\mathrm{MAPbI}_{3}\right)$ is today considered the most promising component for highly efficient third generation solar cells. However, the lifetime of the solar 
devices is strongly affected by the stability of the $\mathrm{MAPbI}_{3}$ films towards humidity, UV irradiation and temperature. The search for efficient protective additives to be used for building up composite perovskite films with enhanced stability is a topic of great interest in the scientific community. In the present paper we have applied a layered zirconium phosphate-phosphonate based on N,N-phosphonomethyl glycine, exfoliated in thin nanosheets (NS), as additive for the stabilization of $\mathrm{MAPbI}_{3}$ crystalline films towards humidity, UV-irradiation and temperature changes. Notably, the additive resulted extremely efficient to prevent degradation of the perovskite film, preserving the optical and structural properties and avoiding the phase transitions normally observed due to temperature increase.

\section{Introduction}

Today more than ever is essential for the mankind to search for renewable energy sources to fulfill the global energy demands and mitigate climate changes. In this sense, solar energy is one of the most promising renewable energy sources. In the last ten years, perovskite solar cells (PSCs) have attracted much attention as a promising innovative photovoltaic technology, possibly contributing to a large scale solar energy production, thanks to their high efficiency and low production costs. ${ }^{[1]}$ Despite their attractive potential, the main drawback of PSCs concerns the durability of the perovskite material, due to instability towards many external factors such as humidity, oxygen, UV light and temperature fluctuations, ${ }^{[2,3]}$ thus resulting in lifetime of perovskite-based devices of barely one year, which do not stand a comparison with silicon solar cell, whose lifetime reaches easily thirty years. ${ }^{[1,4]}$

Therefore, the stabilization of the perovskite material is clearly one of the most crucial issue to be addressed in order to facilitate the commercialization of this technology. More specifically, the aim is to intervene to reduce the chemical instability limiting the formation of defects present in the perovskite, both of which can speed up the process of degradation induced by external factors. ${ }^{[5]}$ 
Several different strategies have been tuned up to meet this goal. One of these focuses on the incorporation of additives directly in the perovskite precursors solution to obtain final materials with enhanced properties. These include, for example, polymers ${ }^{[6,7]}$, cyclodextrins, ${ }^{[8]}$ fullerenes ${ }^{[9,10]}$ and inorganic acids. ${ }^{[11,12]}$ In a recent work, Xie et al. reported the use of some phosphonic acids, like 3-Phosphonopropionic acid, as additives and fabricated a PSC with a power conversion efficiency (PCE) of about $21 \%$ and enhanced device stability due to the presence of $-\mathrm{PO}(\mathrm{OH})_{2}$ group of the additive, which can establish strong hydrogen bonds, passivating shallow point defects and possibly blocking ion migration. ${ }^{[13]}$

A different approach consists in coating the perovskite layer with specific materials, to protect it from external factors while maintaining unchanged its properties. Specifically, a coating layer deposited over the perovskite can act as a barrier by restricting the diffusion of oxygen and moisture and possibly it should protect also from UV light. For example, an ultra-thin layer of $\mathrm{Al}_{2} \mathrm{O}_{3}$ has been deposited on top of the perovskite layer by atomic layer deposition (ALD), prolonging PSCs lifetime with almost no negative effect on device performance, with $90 \%$ of PCE preserved after storage in air for 24 days. ${ }^{[14]}$ Interestingly, when these materials are deposited as nanosheets (NS), they rely on the phenomenon of quantum tunneling to maintain good electron transport properties, while possibly providing moisture protection to the perovskite layer depending on their hydrophobic nature.

Therefore, the choice of an additive or a coating agent capable of improving the stability of the perovskite against detrimental environmental conditions with deposition of thin layers to ensure the electronic conduction by tunnel effect, is a highly desirable goal.

Zirconium phosphonates are a class of compounds already used for a large number of applications, ranging from intercalation, proton conductivity, fillers for nanocomposites and catalysis. $^{[15]}$ In particular, a mixed phosphate-phosphonate based on N,Nbis(phosphonomethyl)glycine (or glyphosine) (L) and with formula $\mathrm{Zr}_{2}\left(\mathrm{PO}_{4}\right)(\mathrm{L})_{2} \bullet \mathrm{H}_{2} \mathrm{O}$ (hereafter ZPGly) ${ }^{[16]}$ was recently used as support for metal nanoparticles in heterogenous 
catalyst. ${ }^{[17-20]}$ The prolonged contact with amine solution (such as propyl amine, $\mathrm{PrNH}_{2}$ ) lead to facile exfoliation of the compound thus forming NS of about $3 \mathrm{~nm}$, which is compatible with the stacking of 2 or 3 single layers. ${ }^{[17]}$ Given such desirable properties of ZPGly, in this work, we investigate its possible stabilization of a $\mathrm{MAPbI}_{3}$ perovskite, deposited either on glass or silicon substrate, both by coating ZPGly NS as thin layer and by including them as additives directly in the perovskite precursors solution.

The detailed structure of ZPGly was already reported elsewhere. ${ }^{[16]}$ It consists in packing of complex hybrid layers of about $15 \AA$ of thickness, built from the connection of $\mathrm{ZrO}_{6}$ octahedra, $\mathrm{PO}_{4}$ tetrahedra and $\mathrm{PO}_{3} \mathrm{C}$ phosphonate tetrahedra belonging to the glyphosine ligands.

\section{(Figure 1)}

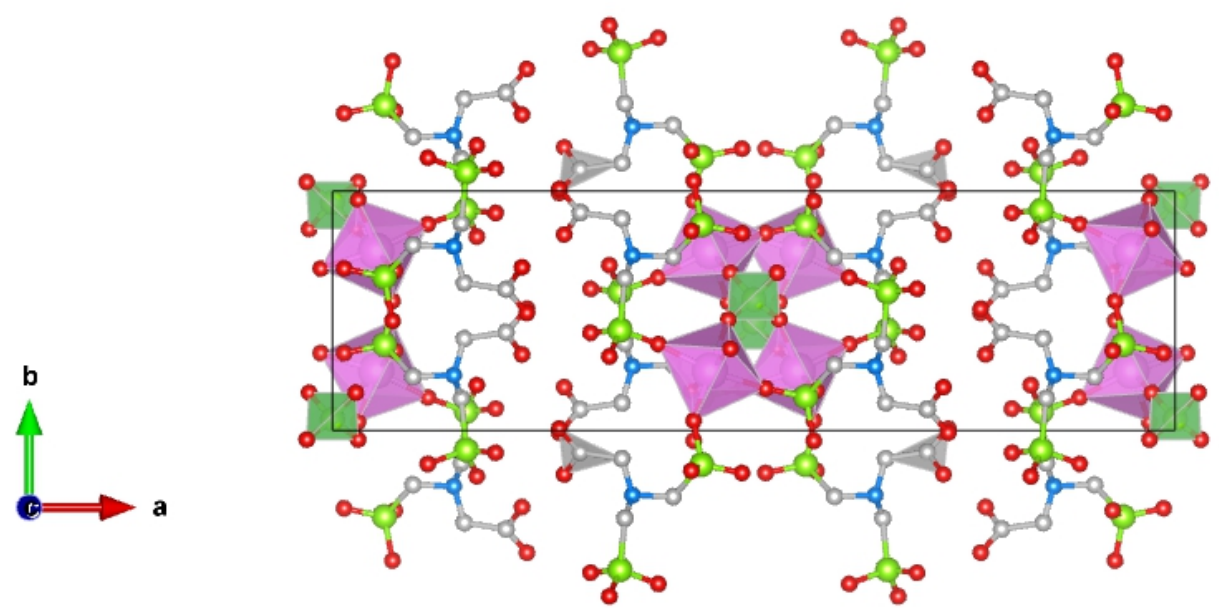

Figure 1. Polyhedral representation of ZPGly-a viewed along the $c$-axis. $\mathrm{ZrO}_{6}$ octahedra are in purple, $\mathrm{PO}_{4}$ tetrahedra are in green. Colour codes: $\mathrm{P}$ green, $\mathrm{C}$ grey, $\mathrm{O}$ red, $\mathrm{N}$ blue. $\mathrm{H}$-atoms are omitted for clarity.

The compound also owns three acid protons per unit formula attributable to the carboxylic groups and to $\mathrm{P}-\mathrm{OH}$ groups. Due to the presence of such acidic protons, the calculated ion exchange capacity (IEC) of the compound is $3.67 \mathrm{meq} / \mathrm{g}$. Moreover, the carboxylic and amino groups can efficiently coordinate transition metal ions, having a high affinity towards them: ${ }^{[16]}$ 
in this way, the presence of $-\mathrm{COOH}$ and $-\mathrm{PO}_{3} \mathrm{H}_{2}$ free moieties can result in reduced toxicity associated to lead release, coordinating $\mathrm{Pb}^{2+}$ ions when perovskites degrade.

ZPGly NS stable dispersion are obtained upon exfoliation of the ZPGly crystalline precursor in $\mathrm{N}, \mathrm{N}$-dimethylformamide (DMF) and then used as coating agent for crystalline $\mathrm{MAPbI}_{3}$ perovskite deposition or mixed with perovskite precursors solution before crystallization. The samples are tested throughout several experimental techniques, i.e. X-Ray Powder Diffraction (XRPD), Thermogravimetric Analysis (TGA) Differential Scanning Calorimetry (DSC), Scanning Electron Microscopy (SEM), UV-Vis, and Luminescence, before and after fast aging treatments in terms of temperature, UV irradiations, relative humidity (RH) and addition of an $\mathrm{I}^{-} / \mathrm{I}_{3}{ }^{-}$electrolyte. The addition of $\mathrm{Zr}$ phosphonate NS results to strongly enhance the $\mathrm{MAPbI}_{3}$ stability in all the experimental conditions.

\section{Result and Discussions}

Two different procedures were carried out in order to build the Perovskite/ZPGly composite by using ZPGly NS gel both as coating agent or by using it as a physical mixture with the $\mathrm{MAPbI}_{3}$ solution (see materials and methods section). Samples, hereinafter, are named as follow: the crude $\mathrm{MAPbI}_{3}, \mathbf{P V K}, \mathrm{MAPbI}_{3}$ coated with ZPGly NS, PVK@ZPGly, and $\mathrm{MAPbI}_{3}$ mixed with ZPGly gel, MIX.

XPRD patterns of the crude PVK, of the coverage PVK@ZPGly and of the MIX are shown in figure 2 The presence of the ZPGly phase does not interfere with the structure and crystallinity of perovskite crystals. The presence of weak reflections in thePVK@ZPGly sample, approximately at $5^{\circ}$ is an evidence of the presence of exfoliated ZPGly. 


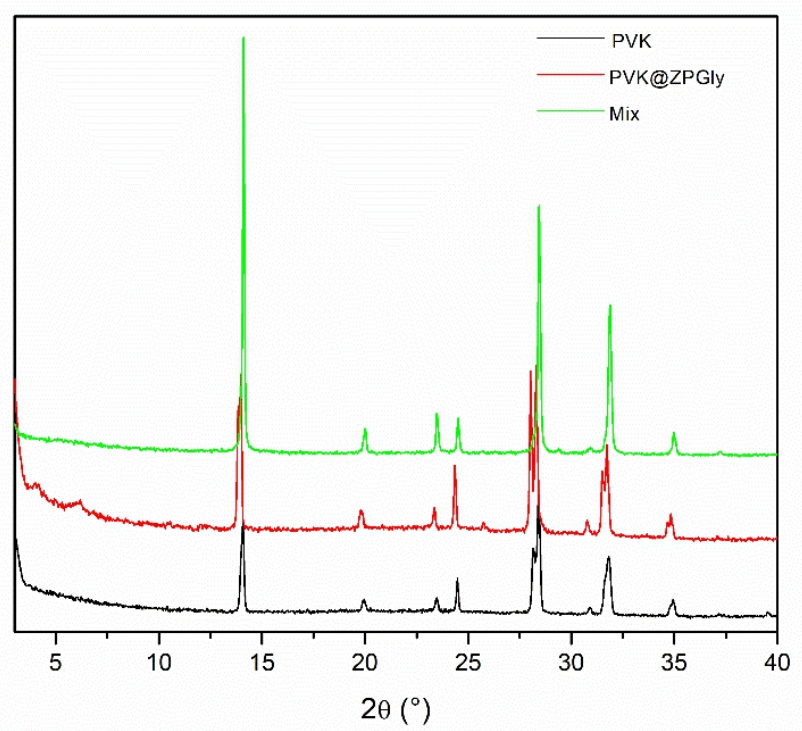

Figure 2. XRPD patterns of PVK crystalline deposition (black), PVK@ZPGly (red) and MIX (green).

Figure 3 shows the SEM images and the Energy-dispersive X-ray spectroscopy (EDX) of the samples. PVK (a) has grown in the form of highly aligned fibers made by crystals with tetragonal structure. The growth in form of fibers is consistent with the data already reported in literature. ${ }^{20}$ Figure 3b shows a section of PVK@ZPGly composite and from EDX analysis the interface between the two materials can be easily seen. On the contrary, in the MIX sample (Figure 3c) the perovskite and ZPGly are mixed evenly, as confirmed by EDX analysis which show a homogeneous distribution of the $\mathrm{Zr}$ and $\mathrm{Pb}$ in the sample. After preparing all the samples, the work has proceeded by testing the stability of the protected perovskites against some factors known for threaten the stability of the perovskite alone, ${ }^{21}$ namely humidity, UV radiation and temperature. In addition, we conducted test to check the stability towards redox-active electrolyte $\mathrm{I}^{-} / \mathrm{I}_{3}{ }^{-}$as reported in Supporting Information (SI). 


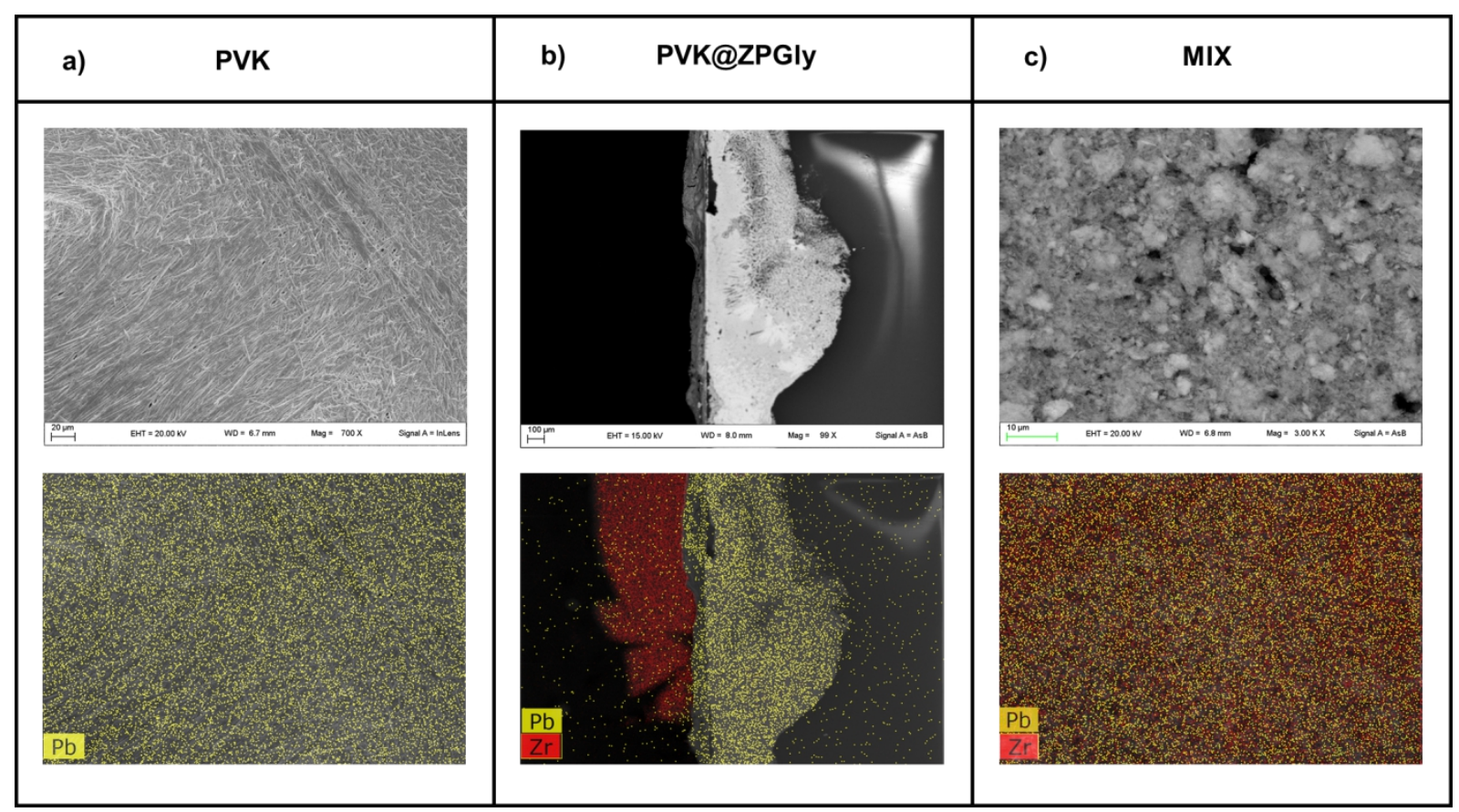

Figure 3. SEM images and relative EDX analysis of a) PVK, b) PVK@ZPGly and c) MIX samples.

\subsection{Stability tests}

\subsubsection{Relative Humidity (RH) Stability}

The samples were placed in a desiccator at $75 \% \mathrm{RH}$ and were monitored through recording of XRD spectra over time. The degradation of crude PVK, as a result of the interaction with humidity, is visible to the naked eye (see pictures of the samples in figure $\mathbf{4 A}$ ) by the evident color changes. 


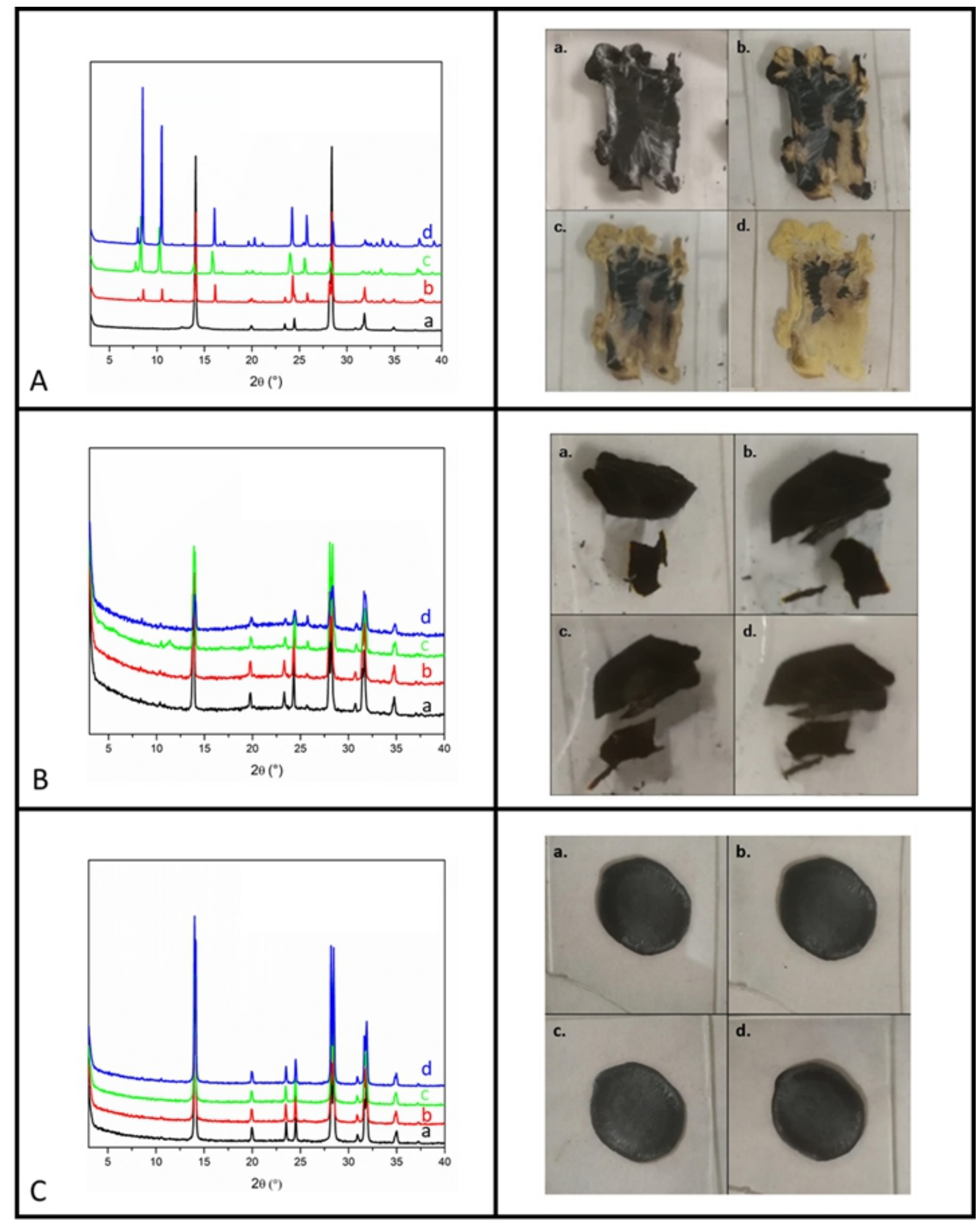

Figure 4. XRD pattern (left) and photos (right) of sample exposed to $75 \%$ RH A) PVK B) PVK@ZPGly and C) MIX; time 0 (a, black), after 1 day (b, red), 6 days (c, green), and 38 days (d, blue). 
The evident degradation of the PVK sample after one day in the desiccator can be observed. XRPD patterns of the sample through time are also shown in the figure. The trend over time of the patterns shows the decrease of the intensity of the peak belonging to the pristine perovskite, notably the (001) and (002) at $14.02^{\circ}$ and $28.34^{\circ} 2 \theta$, respectively. On the other hand, some other peaks appeared and increased over time, specifically those at $7.93^{\circ}, 8.42^{\circ}$, $10.46^{\circ}$ and $16.01^{\circ}$ : these peaks cannot be assigned to either the $\mathrm{MAPbI}_{3}$ or $\mathrm{PbI}_{2}$, but possibly to an intermediate phase. Notably, several studies have been reported in literature about the mechanism of degradation of perovskite due to humidity resulting in the formation of $\mathrm{PbI}_{2}$. According to these studies, ${ }^{[22,23]}$ the degradation starts with the formation of a hydrate phase of the perovskite with structural formula $\left(\mathrm{CH}_{3} \mathrm{NH}_{3}\right)_{4} \mathrm{PbI}_{6} \cdot 2 \mathrm{H}_{2} \mathrm{O}$ from the reaction (1):

$$
\mathrm{CH}_{3} \mathrm{NH}_{3} \mathrm{PbI}_{3}+\mathrm{H}_{2} \mathrm{O} \rightarrow\left(\mathrm{CH}_{3} \mathrm{NH}_{3}\right)_{4} \mathrm{PbI}_{6} \cdot 2 \mathrm{H}_{2} \mathrm{O}
$$

The structure of this phase was characterized by Vincent et al. and it consists of an assembly of $\mathrm{PbI}_{6}{ }^{4-}$ octahedra interspersed with $\mathrm{CH}_{3} \mathrm{NH}_{3}{ }^{+}$cations and water molecules, with each water molecule forming two hydrogen bonds with two $\mathrm{CH}_{3} \mathrm{NH}_{3}{ }^{+}$cations ${ }^{[24]}$. $\left(\mathrm{CH}_{3} \mathrm{NH}_{3}\right)_{4} \mathrm{PbI}_{6} \cdot 2 \mathrm{H}_{2} \mathrm{O}$ is a pale yellow crystalline solid and its XRPD pattern is in line with those we show in Figure 4A. Interestingly, at this level the degradation of perovskite is somewhat reversible: by removing the PVK sample from the desiccator, it is possible to see the yellow sample turning black again. To verify the reversibility of the reaction, the PVK sample was placed outside the desiccator after 42 days of storage and left at ambient conditions for 10 days. From the XRPD spectra (Figure S4, SI), we can see that the peaks belonging to the perovskite, that are basically absent from the spectrum of the sample just took out of the desiccator (black line), grow over time, as it is expected since the $\mathrm{RH}$ is lower in ambient conditions. Whereas, the peaks of the hydrate phase decrease, till the point of being completely absent in the case of the 
sample kept at ambient humidity for 10 days (blue line). Therefore the PVK seems to regenerate but the intensity of the peaks is lower probably due to a partial amorphization.

In contrast to the crude PVK, the sample PVK@ZPGly did not show any color change, and it could indicate that the sample has not undergone any degradation. As a confirmation, XRPD pattern are shown in figure 4B. From the XRPD patterns, the crystalline structure of the perovskite was preserved and no other peaks associated with the hydrate phase or with $\mathrm{PbI}_{2}$ appeared. All the peaks intensities are comparable meaning that no amorphization occurred, contrary to the case of PVK.

Also, in the case of MIX, in images (Figure 4C) the sample does not seem to have suffered any degradation and the XRPD patterns recorded over time confirm it.

\subsubsection{UV irradiation Stability}

It has been extensively reported in literature that $\mathrm{UV}$ radiation induces degradation of $\mathrm{MAPbI}_{3}$ perovskite resulting in the formation of $\mathrm{PbI}_{2}{ }^{[24]}$ The test of stability has been conducted, following a previous work by Kajal et al., exposing the samples to direct UV irradiation at a wavelength of $392 \mathrm{~nm}$ (where perovskite crystals absorb, see below) and an intensity of approximately $350 \mathrm{~mW} / \mathrm{cm}^{2} .^{[25]}$ During the experiment, temperature and humidity were maintained at ambient conditions. The samples were monitored for 12 hours by recording XRPD patterns. Figure 5A (right box) shown mere PVK at various time of UV-radiation exposure.

It is evident from both the images and the spectra that the sample had undergone severe degradation after only 12 hours. 


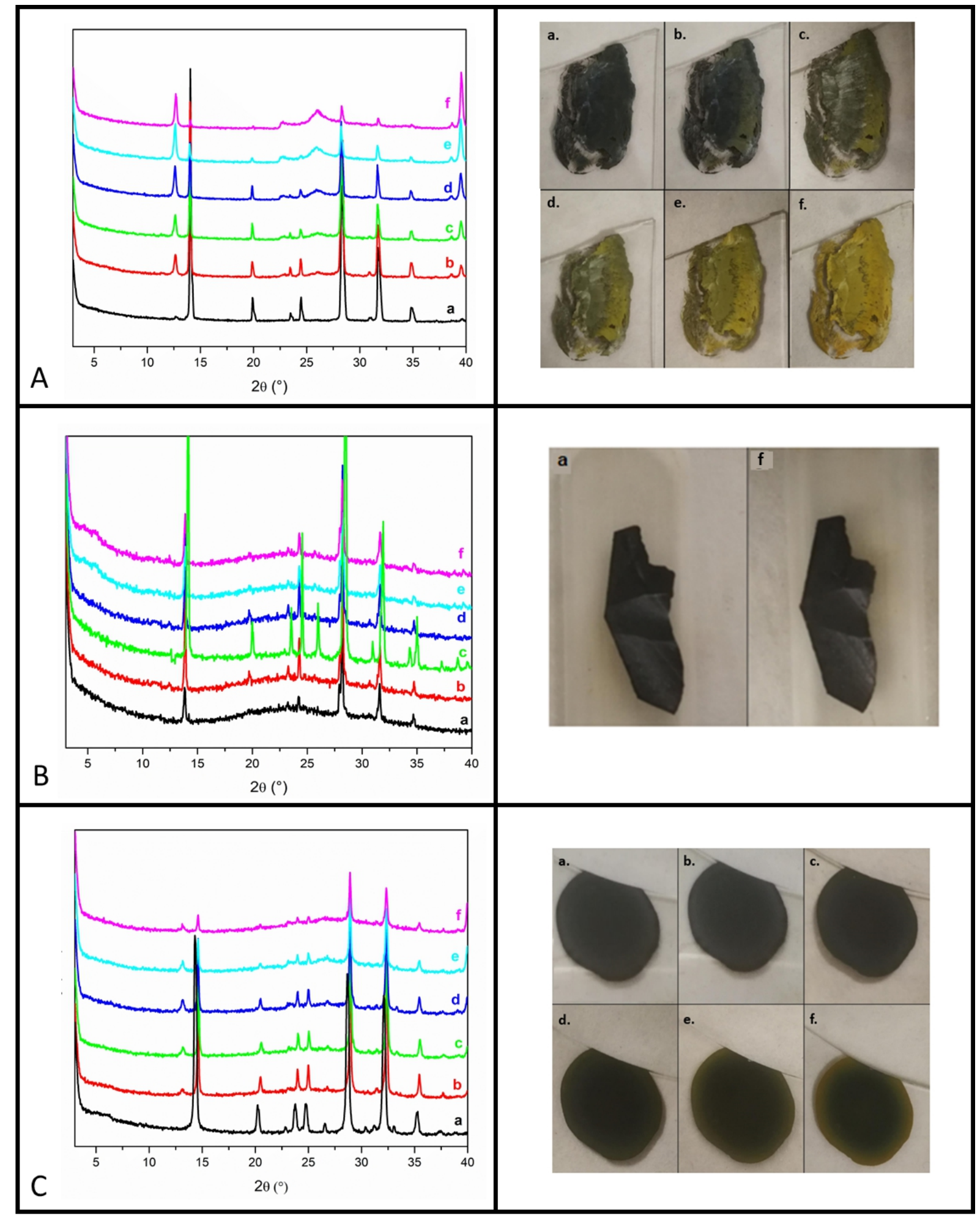

Figure 5. XRPD pattern (left) and photos (right) of sample exposed to UV rays A) PVK, B) PVK@ZPGly and C) MIX; time 0 (a, black), time 1h (b, red), time 2h (c, green), time 3h (d, blue), time 6h (e, cyan), time $12 \mathrm{~h}$ (f, magenta) 
Peaks of the perovskite, in XRPD patterns (Figure 5A left box), decrease gradually with the prolonged time of irradiation, instead only after one hour the peaks belonging to $\mathrm{PbI}_{2}$, particularly the characteristic peak at $12.64^{\circ}$, become visible and increase. After 12 hours of exposition to UV radiation, the PVK crystals appeared almost completely degraded to $\mathrm{PbI}_{2}$.

Contrary to the mere PVK, the PVK@ZPGly remains stable for all the 12 hours as it is shown from both the images and XRPD patterns (figure 5B).

In XRPD pattern reported in figure 5A the appearance of peaks characteristic of $\mathrm{PbI}_{2}$ can be detected and their increase over time indicates degradation of PVK. But comparing the degradation undergone in this sample with the degradation observed in the neat PVK sample, a different level of degradation can be hypothesized. While the PVK is almost completely degraded, the MIX seems to be degraded in a lower degree, as yellow color is observed only on the external part of the crystals.

\subsubsection{Temperature Stability}

The thermal behavior of the mere and protected perovskite was studied through TGA and DSC. First, the TGA heating curves of PVK, ZPGly@PVK and MIX are shown, see Figure 6. 


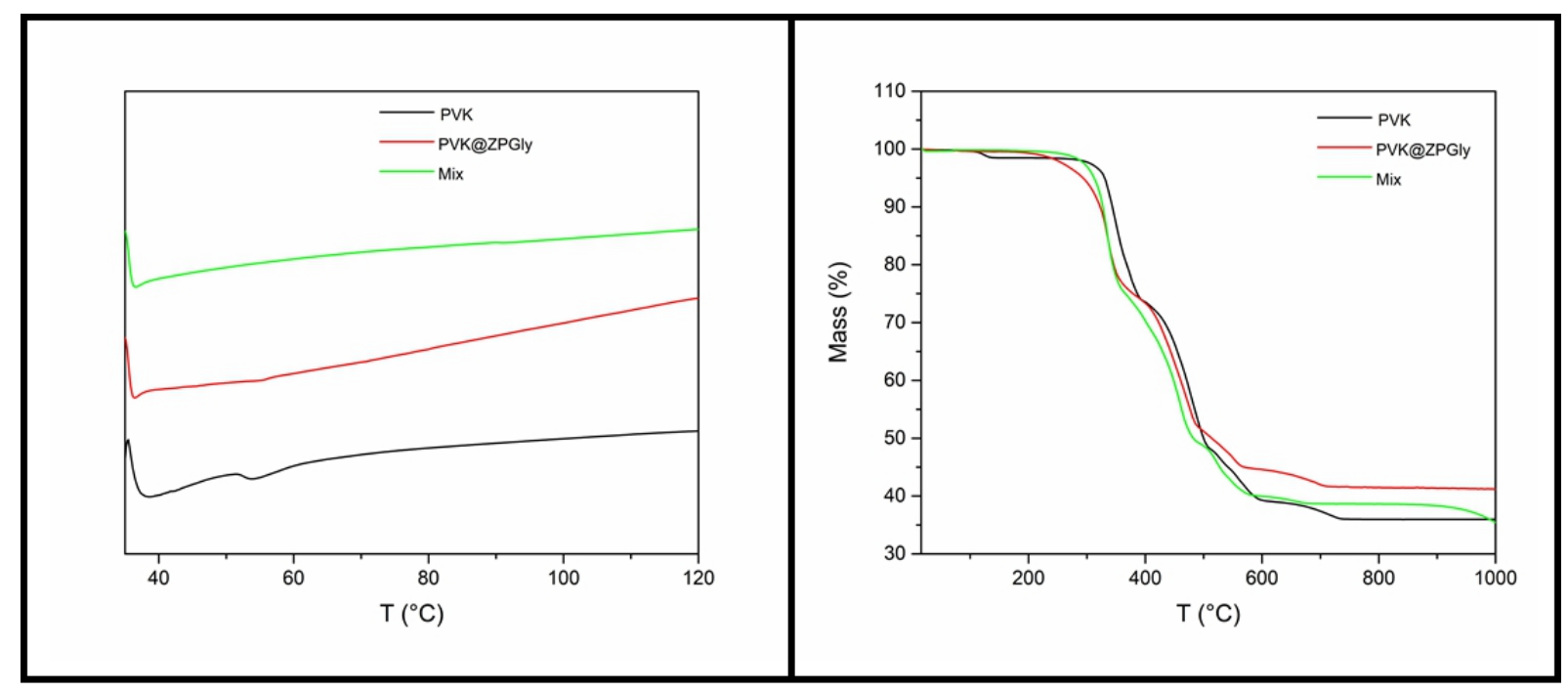

Figure 6. TGA heating curves (left box) and DSC curves (right box) of PVK (Black), PVK@ZPGly (Red) and MIX (Green).

The DSC curve of PVK shows a peak around $55{ }^{\circ} \mathrm{C}$ corresponding to the exothermic phase transitions from tetragonal to cubic phase. ${ }^{[26]}$

Instead, the DSC curves of the protected perovskite do not show the phase transition peak suggesting that ZPGly NS, either as coating or mixed phase, might stabilize the tetragonal phase, since the XRPD patterns confirm that the perovskites, mere and protected, were in tetragonal phase before the DSC analysis. Avoiding the phase transitions, and therefore structural instability and lattice distortion caused by temperature fluctuation, can lead to an enhancement of performance of the perovskite ${ }^{[27]}$. (Figure 6 left box),

By comparing the TGA curves (Figure 6, right box), no remarkable differences can be seen and the pattern is basically the same for all three samples. The major weight losses are at around $220{ }^{\circ} \mathrm{C}$ and $430{ }^{\circ} \mathrm{C}$ and could be assigned to the loss of MAI and $\mathrm{PbI}_{2}$, respectively ${ }^{24}$. There is only a little weight loss around $125{ }^{\circ} \mathrm{C}$ of about $10 \%$ already present in the curve of the PVK sample and absent in the other two curves.

This weight loss can be assigned to the DMF $\operatorname{loss}^{[26]}$ and its absence in the curves of the composites means that ZPGly could facilitate the evaporation of DMF during the synthesis while in the PVK sample a residue of DMF remains. 


\subsection{Optical properties of Perovskite film}

UV-Vis reflectance spectra of perovskite film in absence and presence of ZPGly (prepared with the two methods described below), has been collected immediately soon after the preparation and after $24 \mathrm{~h}$ later exposure to atmospheric conditions (figure 7 ). The optical properties of the PVK@ZPGly film is not modified after 24h exposure to air, while PVK and the MIX film present a detectable alteration in the 250-550 nm region.
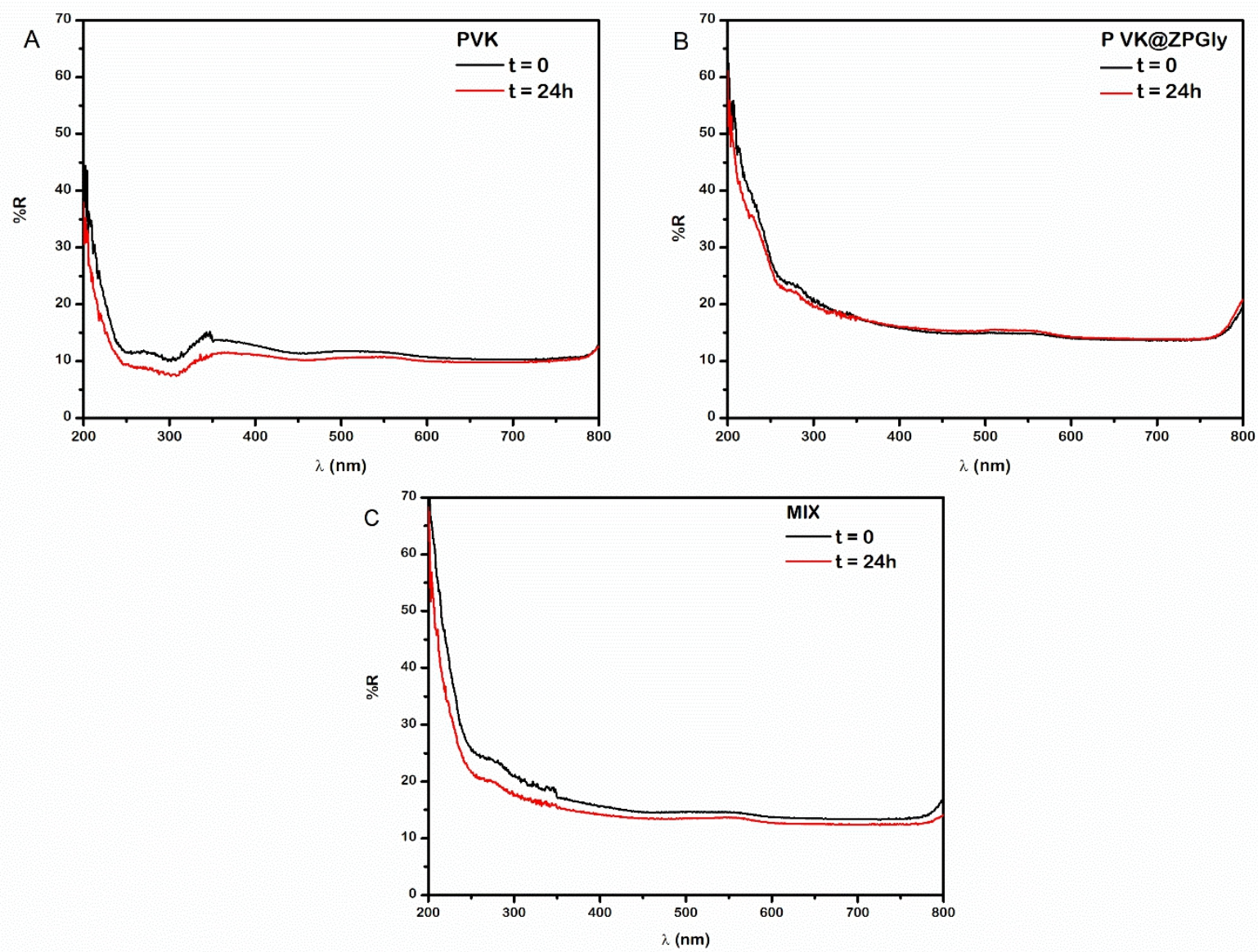

Figure 7. UV-Vis reflectance spectra of PVK (A), PVK@ZPGly (B) and MIX (C) film registered at time 0 (black) and after $24 \mathrm{~h}$ (red).

The spectra of the samples have been registered after taking the samples in environment with the $75 \%$ of RH for 35 days (Figure 8). The PVK films show an impressive alteration of the 
electronic properties, as evidenced by the appearance of absorption bands centred at $380 \mathrm{~nm}$ and $425 \mathrm{~nm}$ (see black line in Figure 8), attributed to the formation of $\mathrm{PbI}_{3}{ }^{-}$and $\mathrm{PbI}_{4}{ }^{2-}$ respectively. ${ }^{[21,28,29]}$

This observation documents the alteration of the optical and electronic behaviors of the neat PVK films due to its chemical instability caused by humidity. The samples with ZPGly (PVK@ZPGly and MIX) do not show such an evident modification in the UV-Vis spectra, confirming the ability of the inorganic coating to preserve the optical properties of the perovskite, protecting it from damages caused by the chemical transformations induced by humidity.

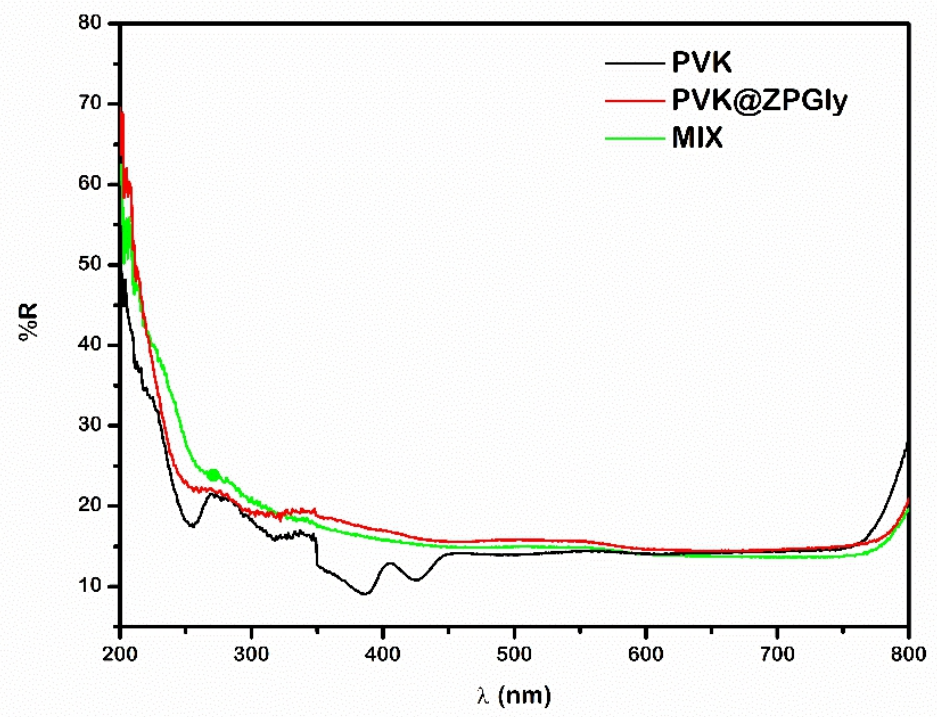

Figure 8. UV-Vis reflectance spectra of PVK (black), PVK@ZPGly (red) and MIX (green) kept in an environment with $75 \%$ of $\mathrm{RH}$ for 35 days.

\section{Conclusion}

A layered zirconium phosphonate based on glyphosine as building block was employed as additive to $\mathrm{MAPbI}_{3}$ crystalline films deposited on silicon or glass support. The advantage of using such material resided in its high versatility to be obtained as stable dispersion of NS 
exposing free carboxylic group, having good affinity towards $\mathrm{Pb}$ ions and being able to efficiently protect the perovskite deposition without interfering with its structural and optical properties. A second synthetic method was also employed and it was based on mixing the $\mathrm{Zr}$ phosphonate gel with the perovskite precursors in order to obtain a physical mixture of the two components. Both methods resulted in a neat improvement of the PVK stability towards humidity, temperature and UV irradiation. XRPD data and UV-Vis spectra confirmed the absence of several degradation products normally observed for unprotected PVK crystals when aged for more than a month at high RH or exposed for several hours to UV irradiation.

Notably, the coating or mixing with ZPGly prevents the tetragonal to cubic phase transition of $\mathrm{MAPbI}_{3}$ observed around $60{ }^{\circ} \mathrm{C}$ which is normally responsible of a general loss of PCE in solar devices due to several reason (density changes causing ruptures, changes in absorption properties etc.). Future developments will be devoted to the use of the composites in PSC devices in order to test the efficiency and eventually to verify an improved stability according to the results reported in the present paper.

\section{Materials and Method}

Analytical and instrumental procedures.

Powder X-Ray Diffraction (PXRD). PXRD patterns were collected in reflection geometry in the $4-40^{\circ} 2 \theta$ range, with a $40 \mathrm{~s} \mathrm{step}^{-1}$ counting time and with a step size of $0.016^{\circ}$ on a PANalytical X'PERT PRO diffractometer, PW3050 goniometer, equipped with an $\mathrm{X}$ 'Celerator detector by using the $\mathrm{Cu} \mathrm{K} \alpha$ radiation. The long fine focus ceramic tube operated at $40 \mathrm{kV}$ and $40 \mathrm{~mA}$. The XRD graph was plotted with Origin Pro 8.5.

Thermogravimetric analysis (TGA).

TGA was performed using a Netzsch STA490C thermoanalyzer under a $20 \mathrm{~mL} \mathrm{~min}{ }^{-1}$ air flux with a heating rate of $10{ }^{\circ} \mathrm{C} \mathrm{min}^{-1}$. 


\section{Differential scanning calorimetry (DSC)}

Differential scanning calorimetry (DSC) analysis was conducted using an automatic DSC1 (Mettler Toledo Switzerland). Aluminum pans with opened lids were employed in the experiments for all the samples and an empty pan was used as a reference. Samples of 3-5 mg were weighted directly into the aluminum pans and the thermal analyses were conducted at a heating rate of $10^{\circ} \mathrm{C} / \mathrm{min}$ from 35 to $120^{\circ} \mathrm{C}$. All runs were carried out under a nitrogen flow of $50 \mathrm{ml} / \mathrm{min}$.

\section{UV-VIS Spectroscopy}

The reflectance spectra were collected by the UV-Vis Varian (Cary 4000), equipped with an external integrated sphere DRA900 (diameter of $150 \mathrm{~mm}$ ), coated by polytetrafluoroethylene (PTFE). A plate of barium sulfate was used as reference.

\section{Scanning electron microscopy (SEM)}

Sample morphology was evaluated using a Scanning Electron Microscopy (SEM) placing the sample on an aluminum stub previously covered with a graphite conductive adhesive. FEG LEO 1525 ZEISS instrument was used.

\section{Chemicals}

All chemicals are commercially available and used without further purification. Hydrofluoric acid (HF) and Phosphoric acid $\left(85 \%\right.$ wt) $\left(\mathrm{H}_{3} \mathrm{PO}_{4}\right)$ were purchased from CarloErba (Italy). Zirconyl chloride $\left(\mathrm{ZrOCl}_{2} \bullet 8 \mathrm{H}_{2} \mathrm{O}\right)$ and Phosphorous acid $\left(\mathrm{H}_{3} \mathrm{PO}_{3}\right)$ were purchased from Alfa Aesar. Lead (II) iodide $\left(\mathrm{PbI}_{2}\right)$, Methylammonium iodide, dimethylformamide (DMF), Glycine, Paraformaldehyde (PFA), hydrochloric acid $(\mathrm{HCl})$ and propylamine were purchased from Sigma Aldrich (Merck).

Synthesis of N,N-Bis(phosphonomethyl)glycine (Glyphosine). Glyphosine was prepared following the Moedritzer-Irani method; ${ }^{[30]} 5 \mathrm{~g}$ of glycine $(67 \mathrm{mmol})$ were dissolved in $50 \mathrm{~mL}$ of $6 \mathrm{M} \mathrm{HCl}$, together with $11 \mathrm{~g}$ of $\mathrm{H}_{3} \mathrm{PO}_{3}(133 \mathrm{mmol})$. This mixture was heated to reflux, and 
$8 \mathrm{~g}$ of paraformaldehyde $(266 \mathrm{mmol})$ dispersed in $10 \mathrm{~mL}$ of water were slowly added within 2 h. After the last addition of paraformaldehyde, the solution was refluxed for 1 more hour and then the solvent was evaporated. The raw mixture was treated with 2-propanol, yielding a white solid that was filtered under vacuum and dried in an oven at $60^{\circ} \mathrm{C} ; 13.6 \mathrm{~g}$ of glyphosine was recovered. (Yield $=74 \%)$.

Synthesis of $\left(\mathrm{Zr}_{2}\left(\mathrm{PO}_{4}\right)\right)(\mathrm{L})_{2} \cdot \mathrm{H} 2 \mathrm{O}(\mathrm{ZPGly})$. The synthesis of ZPGly was achieved as reported in the reference. ${ }^{[16,30]}$ In particular, $2.37 \mathrm{~g}(9 \mathrm{mmol})$ of N,N-bis(phosphonometyl)glycine (L) were dissolved in $93 \mathrm{ml}$ of deionized water $(0.097 \mathrm{M})$, and then $6 \mathrm{ml}$ of phosphoric acid $1 \mathrm{M}$ were add to this solution. $1.93 \mathrm{~g}(6 \mathrm{mmol})$ of $\mathrm{ZrOCl}_{2} \cdot 8 \mathrm{H}_{2} \mathrm{O}$ were dissolved in $20.4 \mathrm{ml}$ of $\mathrm{HF}$ $2.9 \mathrm{M}(59 \mathrm{mmol})$, molar ratio $\mathrm{HF} / \mathrm{ZrIV}=10$. These two solutions were mixed in a $500 \mathrm{~mL}$ Teflon bottle and placed in an oven at $90{ }^{\circ} \mathrm{C}$. After three days the solid was filtered under vacuum, washed three times with deionized water, and dried at $60{ }^{\circ} \mathrm{C}$ for $24 \mathrm{~h}$. The empirical formula was $\mathrm{Zr}_{2} \mathrm{P}_{5} \mathrm{O}_{21} \mathrm{C}_{8} \mathrm{~N}_{2} \mathrm{H}_{19}\left(\mathrm{FW}=816 \mathrm{~g} \cdot \mathrm{mol}^{-1}\right.$, IEC=3.67 mmol/g)

Preparation of ZPGly dispersion. $1 \mathrm{~g}$ of ZPGly $(1.23 \mathrm{mmol})$ was suspended in $108 \mathrm{ml}$ of deionized water and then $22 \mathrm{ml}$ of $n$-propylamine $0.1 \mathrm{M}(2.2 \mathrm{mmol}$ corresponding to $60 \%$ of IEC) were added under vigorous magnetic agitation. A stable dispersion was obtained.

\section{Preparation of Perovskite}

The synthesis of $\mathrm{MAPbI}_{3}$ was carried by slow evaporation in DMF. The 1:1 equivalents of MAI (0.954g) and $\mathrm{PbI}_{2}(2.766 \mathrm{~g})$ were mixed in $5 \mathrm{ml}$ solvent, then the solvent was slowly evaporated in an oven at $70^{\circ} \mathrm{C}$. During the solvent evaporation initially a yellow solid was formed and then turned black. ${ }^{[25]}$

Preparation of Perovskite/ZPGly composites:

Method one (PVK@ZPGly): a film of ZPGly was prepared by deposition of the solution of exfoliated ZPGly in DMF above a silicon support. When the film was completely dry 
perovskite grow above the film by drop casting method ${ }^{[30]}$ and following evaporation of the solvent at $70{ }^{\circ} \mathrm{C}$.

Method two (MIX): the perovskite precursors were mixed together with the ZPGly gel to obtain a homogeneous solution. After that the solution is deposited on a glass or silicon support and placed at $70^{\circ} \mathrm{C}$ to let the DMF evaporate. As a result of the slow evaporation, the film of perovskite and ZPGly is formed in different phases, one almost exclusively composed by perovskite localized on the edges of the film and another phase composed by a mixture of perovskite and ZPGly which represent the remaining part of the film

\section{Supporting Information}

Supporting Information is available from the Wiley Online Library or from the author.

\section{Acknowledgements}

The Università degli Studi di Perugia and MIUR are acknowledged for financial support to the project AMIS, through the program “Dipartimenti di Eccellenza -2018-2022”.

\section{References}

[1] (Roy, P.; Kumar Sinha, N.; Tiwari, S.; Khare, A. A Review on Perovskite Solar Cells: Evolution of Architecture, Fabrication Techniques, Commercialization Issues and Status. $\begin{array}{llll}\text { Sol. } & \mathbf{2 0 2 0}, & \text { Energy } & \text { 665-688, }\end{array}$ https://doi.org/https://doi.org/10.1016/j.solener.2020.01.080.

[2] Manser, J. S.; Saidaminov, M. I.; Christians, J. A.; Bakr, O. M.; Kamat, P. V. Making and Breaking of Lead Halide Perovskites. Acc. Chem. Res. 2016, 49 (2), 330-338. https://doi.org/10.1021/acs.accounts.5b00455.

[3] Bisquert, J.; Juarez-Perez, E. J. The Causes of Degradation of Perovskite Solar Cells. J. Phys. Chem. Lett. 2019, 10 (19), 5889-5891. https://doi.org/10.1021/acs.jpclett.9b00613. 
[4] Grancini, G.; Roldán-Carmona, C.; Zimmermann, I.; Mosconi, E.; Lee, X.; Martineau, D.; Narbey, S.; Oswald, F.; De Angelis, F.; Graetzel, M.; Nazeeruddin, M.K. One-Year Stable Perovskite Solar Cells by 2D/3D Interface Engineering. Nat. Commun. 2017, 8 (1), 15684. https://doi.org/10.1038/ncomms15684.

[5] Li, N.; Niu, X.; Chen, Q.; Zhou, H. Towards Commercialization: The Operational Stability of Perovskite Solar Cells. Chem. Soc. Rev. 2020, 49 (22), 8235-8286. https://doi.org/10.1039/d0cs00573h.

[6] Masi, S.; Rizzo, A.; Aiello, F.; Balzano, F.; Uccello-Barretta, G.; Listorti, A.; Gigli, G.; Colella, S. Multiscale Morphology Design of Hybrid Halide Perovskites through a Polymeric Template. Nanoscale 2015, $7 \quad$ (45), 18956-18963. https://doi.org/10.1039/C5NR04715C.

[7] Guo, Y.; Shoyama, K.; Sato, W.; Nakamura, E. Polymer Stabilization of Lead(II) Perovskite Cubic Nanocrystals for Semitransparent Solar Cells. Adv. Energy Mater. 2016, 6 (6), 1502317. https://doi.org/https://doi.org/10.1002/aenm.201502317.

[8] Masi, S.; Aiello, F.; Listorti, A.; Balzano, F.; Altamura, D.; Giannini, C.; Caliandro, R.; Uccello-Barretta, G.; Rizzo, A.; Colella, S. Connecting the Solution Chemistry of PbI2 and MAI: A Cyclodextrin-Based Supramolecular Approach to the Formation of Hybrid Halide Perovskites. Chem. Sci. 2018, 9 (12), 3200-3208. https://doi.org/10.1039/C7SC05095J.

[9] Chiang, C.-H.; Wu, C.-G. Bulk Heterojunction Perovskite-PCBM Solar Cells with High Fill Factor. Nat. Photonics 2016, 10 (3), 196-200. https://doi.org/10.1038/nphoton.2016.3.

[10] Wang, K.; Liu, C.; Du, P.; Zheng, J.; Gong, X. Bulk Heterojunction Perovskite Hybrid Solar Cells with Large Fill Factor. Energy Environ. Sci. 2015, 8 (4), 1245-1255. https://doi.org/10.1039/C5EE00222B.

[11] Heo, J. H.; Song, D. H.; Han, H. J.; Kim, S. Y.; Kim, J. H.; Kim, D.; Shin, H. W.; Ahn, T. K.; Wolf, C.; Lee, T.-W.; Im, S.H. Planar CH3NH3PbI3 Perovskite Solar Cells with 
Constant 17.2\% Average Power Conversion Efficiency Irrespective of the Scan Rate. $A d v$. Mater. 2015, 27 (22), 3424-3430. https://doi.org/https://doi.org/10.1002/adma.201500048.

[12] Mastria, R.; Colella, S.; Qualtieri, A.; Listorti, A.; Gigli, G.; Rizzo, A. Elucidating the Effect of the Lead Iodide Complexation Degree behind the Morphology and Performance of Perovskite Solar Cells. Nanoscale 2017, $9 \quad$ (11), 3889-3897. https://doi.org/10.1039/C6NR09819C.

[13] Xie, H.; Wang, Z.; Chen, Z.; Pereyra, C.; Pols, M.; Gałkowski, K.; Anaya, M.; Fu, S.; Jia, X.; Tang, P.; Kubicki, D.J.; Agarwalla, A.; Kim, H.; Prochowicz, D.; Borrisé, X.; Bonn, M.; Bao, C.; Sun, X.; Zakeeruddin, S.M.; Emsley, L.; Arbiol, J.; Gao, F.; Fu, F.; Wang, H.I.; Tielrooij, K.; Stranks, S. D.; Tao, S.; Grätzel, M.; Hagfeldt, A.; Lira-Cantu, M. Decoupling the Effects of Defects on Efficiency and Stability through Phosphonates in Stable Halide Perovskite Solar Cells. Joule 2021, 5 (5), 1246-1266. https://doi.org/https://doi.org/10.1016/j.joule.2021.04.003.

[14] Dong, X.; Fang, X.; Lv, M.; Lin, B.; Zhang, S.; Ding, J.; Yuan, N. Improvement of the Humidity Stability of Organic-Inorganic Perovskite Solar Cells Using Ultrathin A12O3 Layers Prepared by Atomic Layer Deposition. J. Mater. Chem. A 2015, 3 (10), 5360-5367. https://doi.org/10.1039/C4TA06128D.

[15] Shearan, S. J. I.; Stock, N.; Emmerling, F.; Demel, J.; Wright, P. A.; Demadis, K. D.; Vassaki, M.; Costantino, F.; Vivani, R.; Sallard, S.; Ruiz Salcedo, I.; Cabeza, A.; Taddei, M. New Directions in Metal Phosphonate and Phosphinate Chemistry. Crystals 2019, 9 (5). https://doi.org/10.3390/cryst9050270.

[16] Donnadio, A.; Nocchetti, M.; Costantino, F.; Taddei, M.; Casciola, M.; da Silva Lisboa, F.; Vivani, R. A Layered Mixed Zirconium Phosphate/Phosphonate with Exposed Carboxylic and Phosphonic Groups: X-Ray Powder Structure and Proton Conductivity Properties. Inorg. Chem. 2014, 53 (24), 13220-13226. https://doi.org/10.1021/ic502473w.

[17] Costantino, F.; Vivani, R.; Bastianini, M.; Ortolani, L.; Piermatti, O.; Nocchetti, M.; 
Vaccaro, L. Accessing Stable Zirconium Carboxy-Aminophosphonate Nanosheets as Support for Highly Active Pd Nanoparticles. Chem. Commun. 2015, 51 (88), 15990-15993. https://doi.org/10.1039/C5CC06292F.

[18] Costantino, F.; Nocchetti, M.; Bastianini, M.; Lavacchi, A.; Caporali, M.; Liguori, F. Robust Zirconium Phosphate-Phosphonate Nanosheets Containing Palladium Nanoparticles as Efficient Catalyst for Alkynes and Nitroarenes Hydrogenation Reactions. ACS Appl. Nano Mater. 2018, 1 (4), 1750-1757. https://doi.org/10.1021/acsanm.8b00193.

[19] Campoccia, D.; Ravaioli, S.; Vivani, R.; Donnadio, A.; Vischini, E.; Russo, A.; Visai, L.; Arciola, C. R.; Montanaro, L.; Nocchetti, M. Antibacterial Properties of a Novel Zirconium Phosphate-Glycinediphosphonate Loaded with Either Zinc or Silver. Materials (Basel). 2019, 12 (19). https://doi.org/10.3390/ma12193184.

[20] Rahimnejad, S.; Kovalenko, A.; Forés, S. M.; Aranda, C.; Guerrero, A. Coordination Chemistry Dictates the Structural Defects in Lead Halide Perovskites. Chemphyschem 2016, 17 (18), 2795-2798. https://doi.org/10.1002/cphc.201600575.

[21] Stewart, R. J.; Grieco, C.; Larsen, A. V; Doucette, G. S.; Asbury, J. B. Molecular Origins of Defects in Organohalide Perovskites and Their Influence on Charge Carrier Dynamics. J. Phys. Chem. C 2016, $120 \quad$ (23), 12392-12402. https://doi.org/10.1021/acs.jpcc.6b03472.

[22] Christians, J. A.; Miranda Herrera, P. A.; Kamat, P. V. Transformation of the Excited State and Photovoltaic Efficiency of $\mathrm{CH} 3 \mathrm{NH} 3 \mathrm{PbI} 3$ Perovskite upon Controlled Exposure to Humidified Air. J. Am. Chem. Soc. 2015, 137 (4), 1530-1538. https://doi.org/10.1021/ja511132a.

[23] Yang, J.; Siempelkamp, B. D.; Liu, D.; Kelly, T. L. Investigation of CH3NH3PbI3 Degradation Rates and Mechanisms in Controlled Humidity Environments Using in Situ Techniques. ACS Nano 2015, 9 (2), 1955-1963. https://doi.org/10.1021/nn506864k.

[24] Vincent, B. R.; Robertson, K. N.; Cameron, T. S.; Knop, O. Alkylammonium Lead 
Halides. Part 1. Isolated PbI64- Ions in (CH3NH3)4PbI6•2H2O. Can. J. Chem. 1987, 65 (5), 1042-1046. https://doi.org/10.1139/v87-176.

[25] Kajal, P.; Ghosh, K.; Powar, S. Manufacturing Techniques of Perovskite Solar Cells. In Applications of Solar Energy; Springer, 2018; pp 341-364.

[26] Dualeh, A.; Gao, P.; Seok, S. Il; Nazeeruddin, M. K.; Grätzel, M. Thermal Behavior of Methylammonium Lead-Trihalide Perovskite Photovoltaic Light Harvesters. Chem. Mater. 2014, 26 (21), 6160-6164. https://doi.org/10.1021/cm502468k.

[27] Baikie, T.; Fang, Y.; Kadro, J. M.; Schreyer, M.; Wei, F.; Mhaisalkar, S. G.; Graetzel, M.; White, T. J. Synthesis and Crystal Chemistry of the Hybrid Perovskite (CH3NH3)PbI3 for Solid-State Sensitised Solar Cell Applications. J. Mater. Chem. A 2013, 1 (18), 5628 5641. https://doi.org/10.1039/C3TA10518K.

[28] Radicchi, E.; Mosconi, E.; Elisei, F.; Nunzi, F.; De Angelis, F. Understanding the Solution Chemistry of Lead Halide Perovskites Precursors. ACS Appl. Energy Mater. 2019, 2 (5), 3400-3409. https://doi.org/10.1021/acsaem.9b00206.

[29] Snaith, H. J. Perovskites: The Emergence of a New Era for Low-Cost, High-Efficiency Solar Cells. J. Phys. Chem. Lett. 2013, 4 (21), 3623-3630. https://doi.org/10.1021/jz4020162.

[30] Moedritzer, K.; Irani, R. R. The Direct Synthesis of $\alpha$-Aminomethylphosphonic Acids. Mannich-Type Reactions with Orthophosphorous Acid. J. Org. Chem. 1966, 31 (5), 16031607. https://doi.org/10.1021/jo01343a067. 


\section{Enhanced Stability of $\mathrm{MAPbI}_{3}$ Perovskite Films with Zirconium Phosphate-}

\section{Phosphonomethylglycine Nanosheets as Additive}

Nadir Vanni, Diletta Morelli Venturi, Eros Radicchi, Giulia Quaglia, Elena Cambiotti, Loredana Latterini, Filippo De Angelis* and Ferdinando Costantino*

Layered Zirconium phosphate-phosphonate based on glyphosine was employed as additive for enhancing the stability of $\mathrm{MAPBI}_{3}$ perovskite deposition

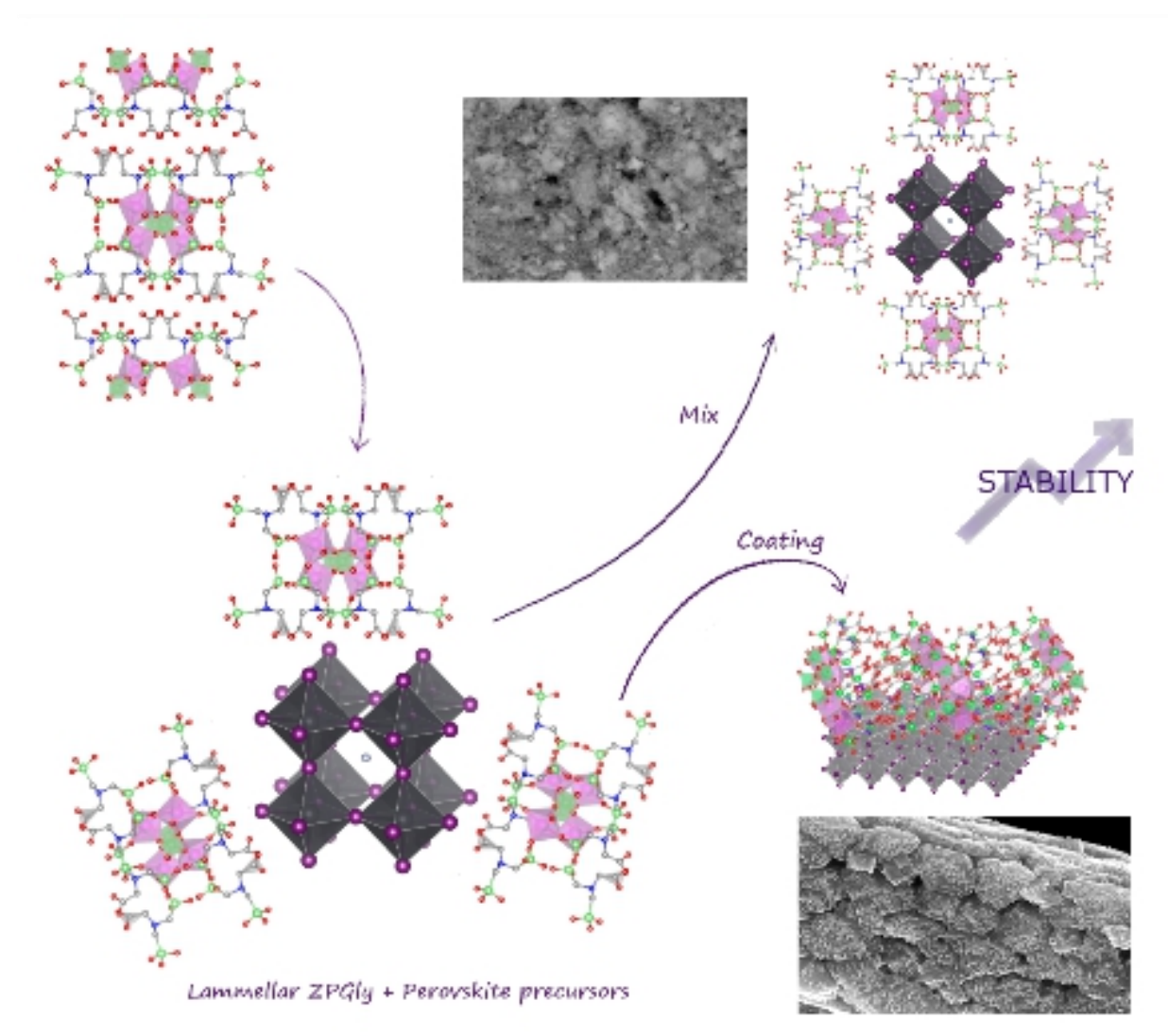

ToC figure 


\section{Supporting Information}

Enhanced Stability of $\mathrm{MAPbI}_{3}$ Perovskite Films with Zirconium PhosphatePhosphonomethylglycine Nanosheets as Additive

Nadir Vanni, Diletta Morelli Venturi, Eros Radicchi, Giulia Quaglia, Elena Cambiotti, Loredana Latterini, Filippo De Angelis* and Ferdinando Costantino* 


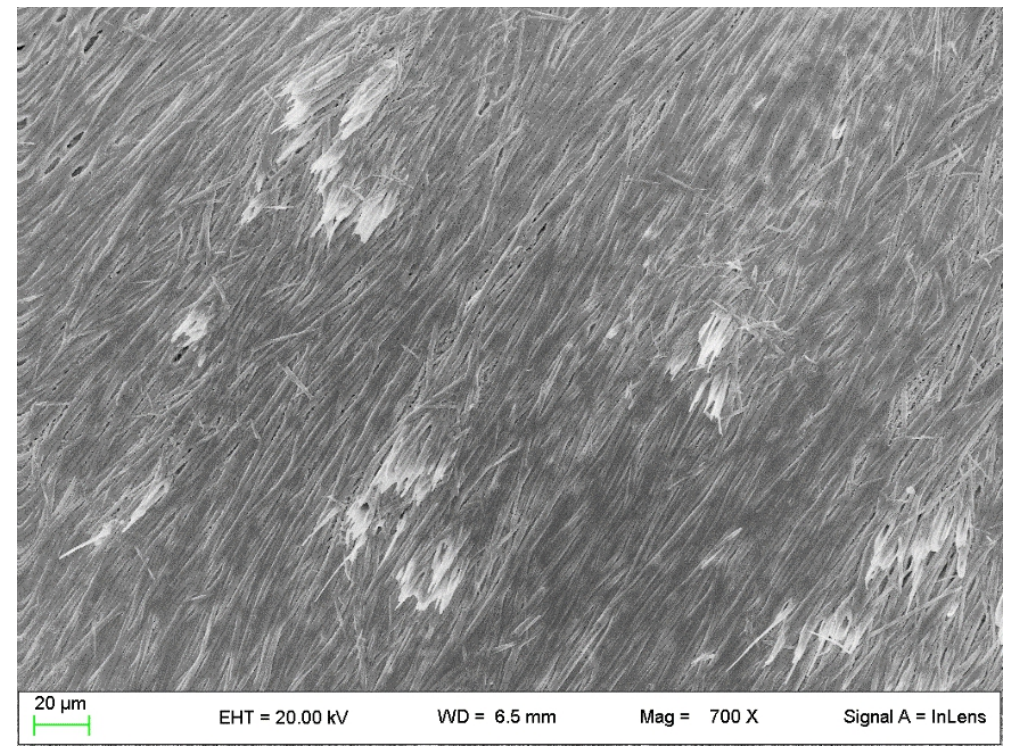

Figure S1. SEM images of PVK

a
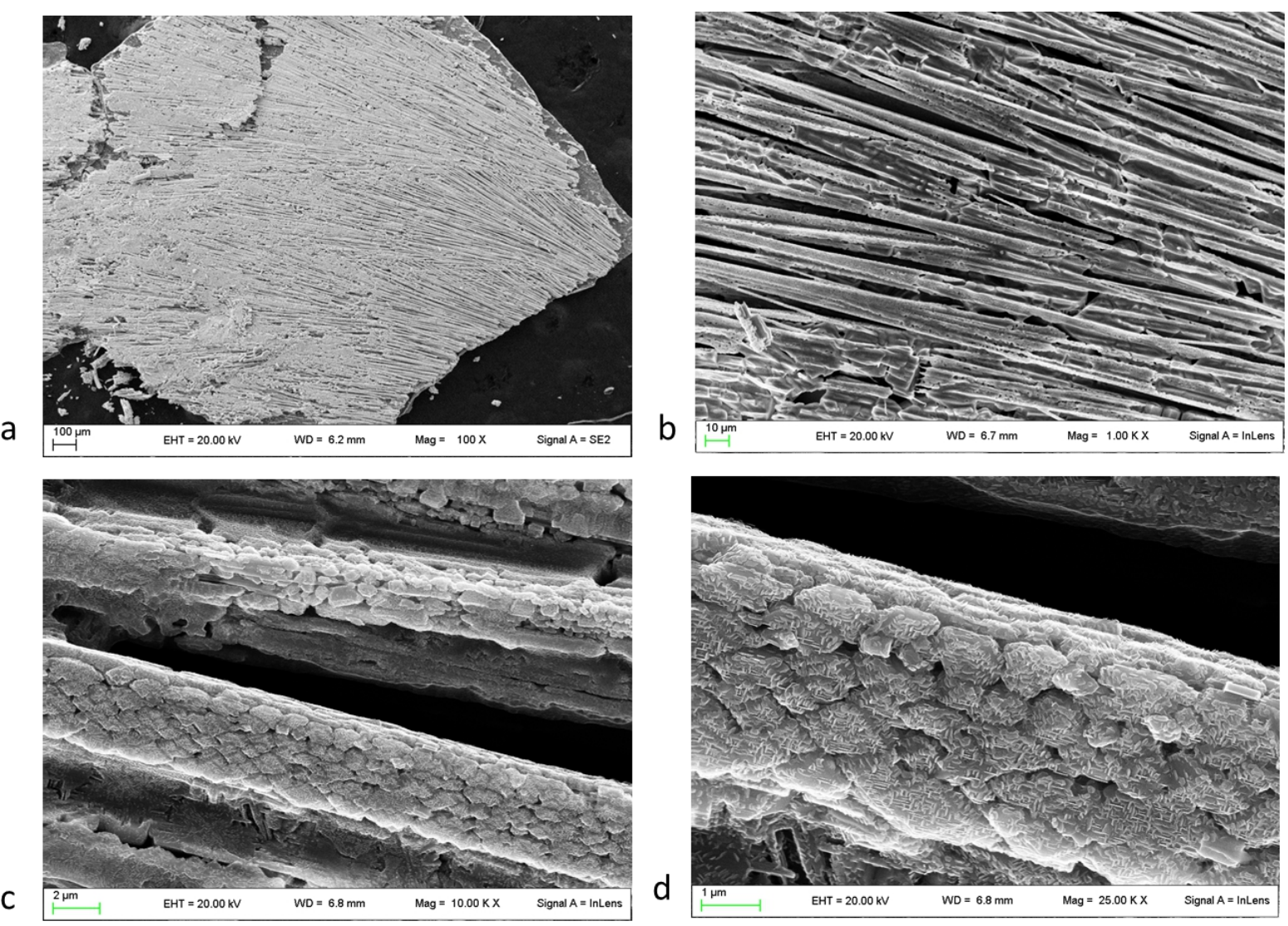

Figure S2. SEM images of PVK@ZPGly 

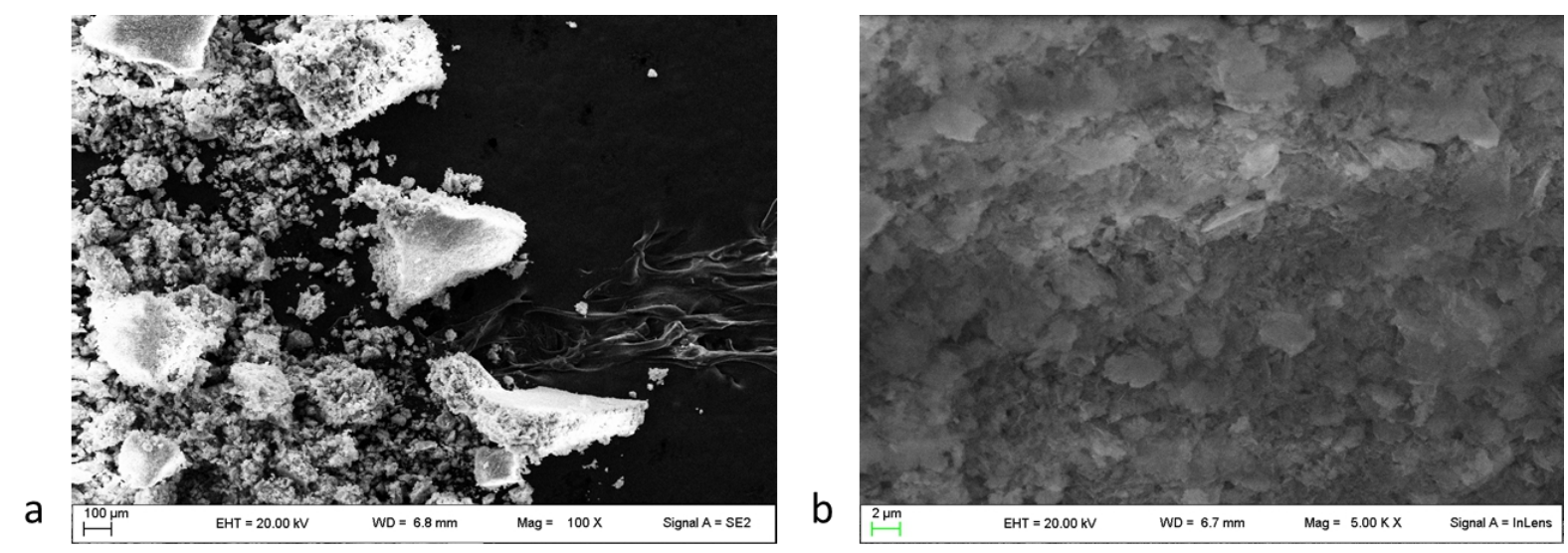

Figure S3. SEM images of MIX

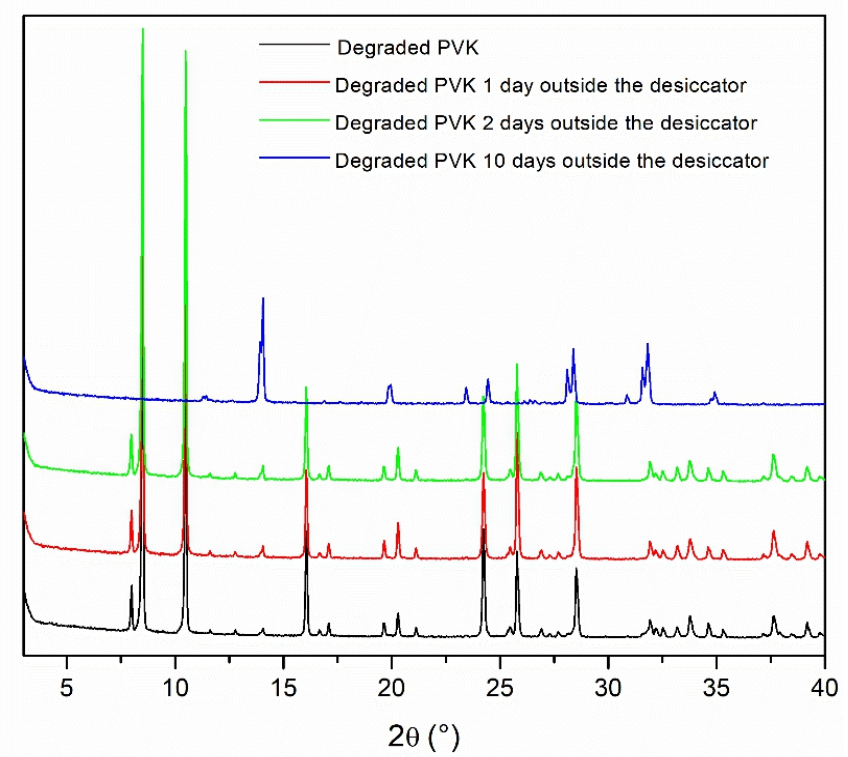

Figure S4. XRPD patterns of a sample of perovskite degraded at $70 \%$ RH and kept at ambient humidity for 10 days.

\section{Electrolyte I/I- Stability}

The first appearance of the category of perovskite in the photovoltaic field was as dye in a dye-sensitized solar cell device. ${ }^{[1]}$ The overwhelming drawback was that the liquid electrolyte dissolved the perovskite in just a few minutes. Therefore, in this work we have tested the stability of the coated perovskite with the goal of recreate a more stable DSSC device using 
the perovskite. To perform the test, we took samples of PVK and of protected perovskite (both PVK@ZPGly and MIX) with similar thickness, and we cover them with the liquid electrolyte making sure that the samples remained covered by the liquid for at least one hour. As expected, the sample of PVK dissolved due to the electrolyte in less than one minute, making impossible even to record a XRPD pattern after the test (Figure S5).

Instead, the samples of coated perovskite did not dissolve after more than one hour in contact with the electrolyte, making also possible to record XRPD spectra before and after the test.

These are basically identical, which indicates that the sample was not damage by the liquid electrolyte. (Figure S6, left)

In the case of MIX spectrum (Figure S6, right) after the contact with the electrolyte the higher peaks of the perovskite are preserved while some of the lower peaks disappeared suggesting that the perovskite was slightly damaged. 


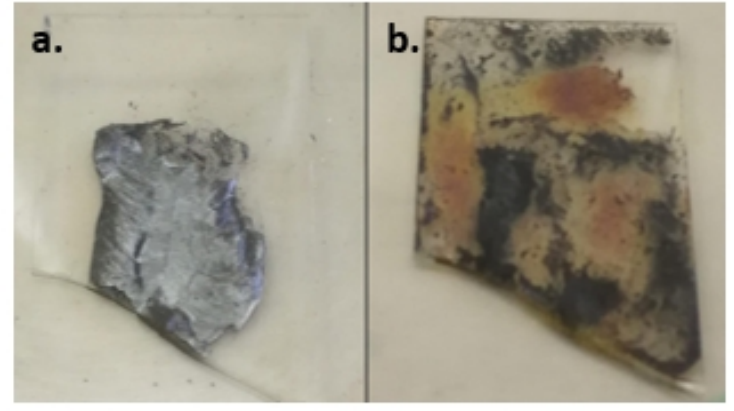

Figure S5. Images of a sample of PVK a) before and b) after the contact with liquid electrolyte.

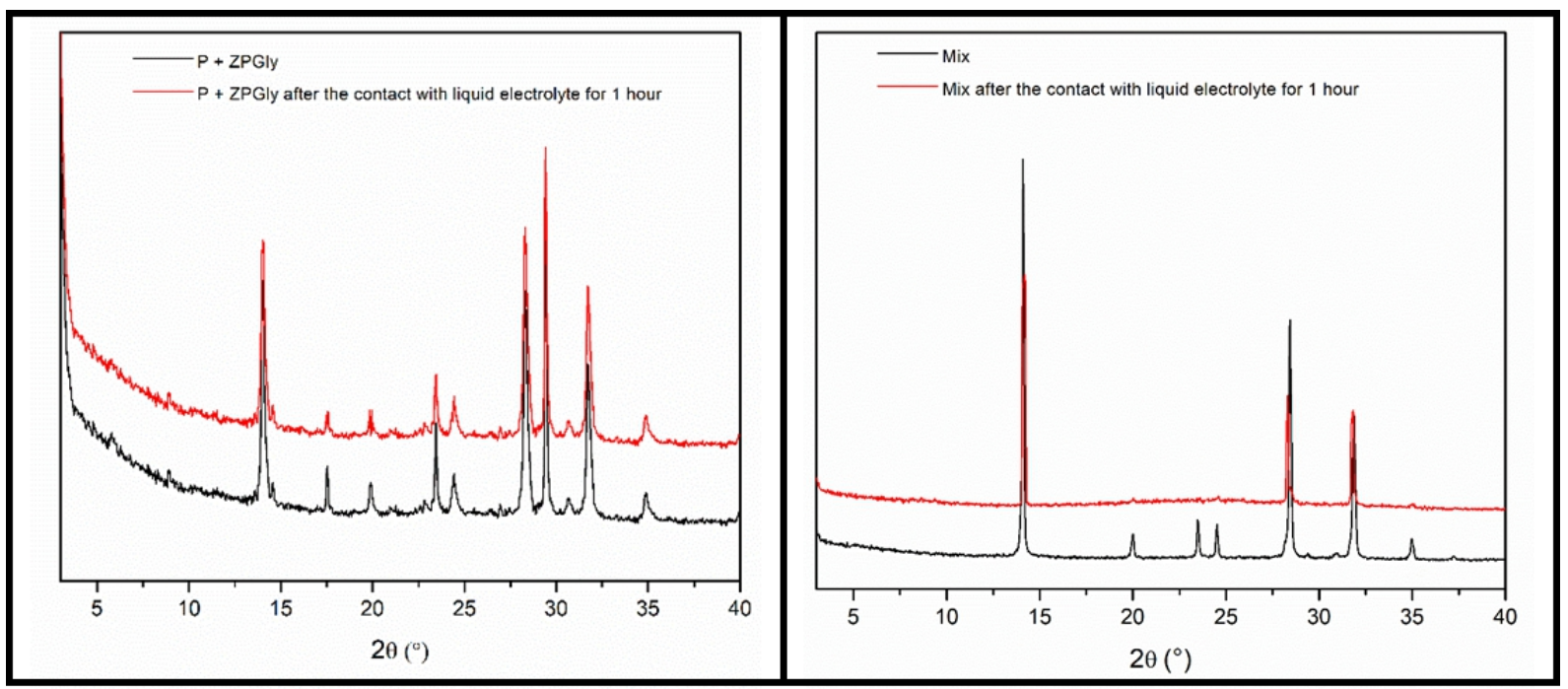

Figure S6. XRD spectra of a sample of PVK@ZPGly (left box) and of MIX (right box) before and after the exposition with liquid redox-active electrolyte $\mathrm{I}^{-} / \mathrm{I}_{3}^{-}$.

References

[1] Yang, J.; Siempelkamp, B. D.; Liu, D.; Kelly, T. L. Investigation of CH3NH3PbI3

Degradation Rates and Mechanisms in Controlled Humidity Environments Using in Situ Techniques. ACS Nano 2015, 9 (2), 1955-1963. https://doi.org/10.1021/nn506864k. 